\title{
Social Support Pairs Predict Daily Functioning Following Traumatic Spinal Cord Injury: An Exploratory Study
}

\author{
Mary A. O’Hare, Lara Wallis and Gregory C. Murphy* \\ School of Public Health, La Trobe University, Bundoora, 3083, Australia
}

\begin{abstract}
Aim: This exploratory study assessed (1) the associations between three major types of social support (perceived, actual and structural) and post-injury daily functioning and (2) the ability of subjective-objective social support dyads to predict rehabilitation outcome among traumatic spinal cord injury (SCI) patients one-year postdischarge.

Method: Using a prospective study design, 20 SCI patients of workforce age discharged from the Royal Talbot Rehabilitation Hospital, Melbourne, Australia during 2007 were assessed on a range of demographic, injury and social support variables. Post-injury daily functioning was assessed 12-months post-discharge.

Results: Bivariate analyses revealed that the three major types of social support were associated with better post-injury daily functioning. Multivariate analyses revealed that the dyad of (subjective) perceived social support and (objective) community integration was the best predictor of successful rehabilitation outcome. For all three social support dyads, the subjective component contributed greater unique variance to the overall predictive ability of the model than did the accompanying objective component.

Conclusions: Use of psychometrically sound scales that incorporate objective and subjective measures of social support may provide a more effective means of evaluating the contribution of social support to rehabilitation outcome, plus indicate whether desired social support levels satisfactorily match those received.
\end{abstract}

Keywords: Actual social support, perceived social support, rehabilitation outcome, structural social support, traumatic spinal cord injury.

\section{INTRODUCTION}

Social support is a multi-faceted meta-construct and its effect on rehabilitation outcomes varies according to which aspect of social support is assessed [1,2]. Research has examined three major types of social support - perceived, actual and structural [3-5]. The use of well-defined and psychometrically sound measures of social support is critical to identifying the nature and extent of social support's relationship to rehabilitation outcomes $[6,7]$. Unfortunately, the use of global, ad-hoc measures of social support has not been uncommon $[1,2,8]$. Although the objective measurement of actual support may capture the true meaning of social support [6], there is mounting evidence that the subjective dimension of social support can either promote or damage health [9-11]. For example, social support potentially confers multiple health-related benefits [12-15], however, the subjectively assessed quality of social support may influence the extent of those benefits [11]. Therefore, in real-world contexts, subjective appraisal of social support likely co-exists with objectively received social support. Unfortunately, subjective perceptions of social support are less frequently assessed than objective measures [13, 16]. Therefore, there is a need for research which (1) assesses the relationship between well-defined forms of social support

*Address correspondence to this author at the School of Public Health, La Trobe University, 3083 Australia; Tel: + 613 94791745; Fax: + 613 9479 1783; E-mail: G.Murphy@latrobe.edu.au and rehabilitation outcomes and (2) examines both the objective and subjective dimensions of social support and their combined ability to predict successful rehabilitation outcomes. The present study sought to fill this research gap by examining the association between well-defined, psychometrically sound measures of the three main types of social support (perceived, actual and structural) and rehabilitation outcome, and by identifying the effectiveness of particular social support dyads (comprising a subjective and objective measure of social support) in the successful prediction of rehabilitation outcome.

\section{SOCIAL SUPPORT}

Social support is generally understood as the support and assistance provided by others [6] which fosters a belief that the individual is loved, esteemed and cared for [12]. The relationship between social support and recovery from illness is well-established [5, 15]. For example, social support reduces and prevents illness [15], provides protection from arthritis, depression, alcoholism, low birth weight and death $[12,17]$ and modifies the detrimental effect of unemployment on mental health $[15,18,19]$. Among SCI survivors, social support also significantly predicted healthrelated quality of life and a reduction in helplessness [20, 21].

Social support is frequently operationalized using objective criteria (e.g., type of assistance or size of network), however, the experiential or subjective dimension of social support (e.g., acceptance and affirmation) is extremely 
important [1]. Subjective perceptions of social support are critical because some social interactions may be negative [9, 19], overwhelming [1, 22] or inadequate [23]. Problematic social interactions, such as disputes and invasion of privacy, may damage well-being, particularly among the chronically ill $[9,13,24]$. For example, interpersonal conflict is linked to depression, withdrawal, and lower resistance to infectious diseases [see Cohen et al., 13].

Therefore, when used as the sole index of social support, objective measures may be inadequate because the quality of social support exchanges may vary and the relationship between social support and health outcomes may be mediated by the recipient's perception or experience of social support [8]. Subjective appraisal of social support may provide important additional information because individual representations or interpretations of social support may differ from those offered, received or available [1,2]. Therefore, the use of social support dyads comprising both an objective and subjective measure of social support may provide a more effective method for assessing the contribution of social support to the prediction of rehabilitation outcome.

\section{OBJECTIVE MEASURES OF SOCIAL SUPPORT}

\section{Structural Social Support}

Structural social support relates to social networks or the number of people with whom an individual has active social ties, whether significant or casual $[2,3,25]$. Structural social support comprises social integration and community integration, with each measuring a different aspect of social embeddedness $[5,26]$. Social integration refers to the level of participation in, and maintenance of, a wide array of social relationships, including family, friends, colleagues and acquaintances $[13,27]$. Community integration refers to more formal ties within the wider community (e.g., church and recreational organisations) and is primarily concerned with status, roles, activities and independence [28]. Therefore, social integration centers on individual and group-level interactions while community integration focuses on community-level interactions [29].

Objective measures have shown that community integration is associated with multiple, broad-range health benefits including protection from cardiovascular disease, stroke, cancer, accidents and suicides [30-32], as well as reducing mortality rate [11]. Similarly, social integration is moderately associated with increased health-related quality of life [21], greater social participation [33] and can be more important for successful adjustment following injury than the severity of the disability or the length of time since the injury [34]. However, the subjectively assessed quality of social and community interaction influences the extent of these health benefits [11].

Measurement of social and community integration is usually objective and includes empirical assessment of the size and density of social networks and the frequency of interaction [13]. However, objective measures of integration may not fully capture the meaning of participation [16]. For example, integration includes the actual social network or environment as well as individuals' representation (i.e., subjective perception) of the social environment [13].
Furthermore, others' reactions (acceptance or withdrawal) influence not only the size of the social network, but also subjective experiences of participation [16]. Inaccessible buildings or surroundings also influence subjective feelings of participation [16]. Furthermore, larger networks do not necessarily provide more or better social support. For example, the average level of social support may be lower in larger communities [35] while the adequacy of social support may not increase with a greater number of social support sources [23]. Unfortunately, subjective perceptions of belongingness are seldom assessed in studies of social and community integration $[13,16]$.

\section{Actual Social Support}

Actual social support includes emotional, informational and instrumental support and is thought to embody the true nature and meaning of social support [6]. Therefore, actual social support should be the most relevant measure of support during distress [13]. However, the relationship between actual support and health is not clear-cut. For example, actual social support is related to both higher and lower symptomology [24, see also Cohen \& Wills 14]. The lack of consistent results may reflect a mismatch between the amount of actual social support needed and the amount received (see Kalinski [36], and the timing of data collection). For example, the relationship between social support and recovery is dynamic [23], therefore, social support needs change during post-injury rehabilitation and adjustment phases as daily habits are established [8].

Actual social support is usually measured objectively by assessing the level of social support and the frequency of social support exchanges [22]. However, the level of actual social support may alter the subjective appraisal of events, and subjective appraisal may be related to adjustment to disability [13]. Therefore, a reliance on purely objective measures may partially account for the equivocal results obtained for the ability of actual social support to predict rehabilitation outcomes.

\section{SUBJECTIVE MEASURES OF SOCIAL SUPPORT}

\section{Perceived Social Support}

Perceived social support assesses perceptions of the availability of social support, and perceived satisfaction with available support [1, 26, 37]. Thus, perceived social support involves subjective appraisal $[1,2]$. Subjective appraisal incorporates individual differences in the need for social support [37-39] as well as the perceived adequacy of available support to match the demands of the stressor [40]. Of the three major types of social support, perceived social support has the strongest relationship to adaptation following adverse health outcomes $[5,24]$. In particular, perceived social support is related to effective coping [41] improved physical and mental health $[15,38,42-44]$, lower mortality rates [30] and a speedier return to work following illness [45]. Perceived social support, therefore, is generally considered to be the "crux" of the social support system [37] and may be even more important than actual social support [46], possibly due to its impact on subjective well-being [42]. 


\section{The Present Study}

The present study examined the rehabilitation outcomes of spinal cord injury survivors. Among this population, traditionally-studied demographic and injury variables explain approximately $35 \%$ of the criterion variance $[47,48]$. Identification of the variables that account for the remaining $65 \%$ of unexplained variance is urgently required from both a researcher and practitioner perspective. Social support may account for some of the remaining difference. For the purposes of analysis, most research has focused on either subjective or objective aspects of social support. However, in naturalistic settings, subjective appraisal of social support likely co-exists with objectively received social support and may influence the extent of its benefit. Therefore, the present study sought to fill this research gap by examining the influence of social support on rehabilitation outcome posttraumatic spinal cord injury. The present exploratory study had two aims. The first aim was to assess the relationship between the three major forms of social support (perceived, actual and structural) and rehabilitation outcome (operationalised as daily functioning ability across six major life domains: work; domestic duties, self-care; mobility; communication; and participation). The second aim of the study was to assess the effectiveness of three different social support dyads (comprising a subjective and objective measure of social support) in the successful prediction of rehabilitation outcome. Three social support subjectiveobjective dyads were examined in the present study: (1) perceived social support and community integration; (2) perceived social support and social integration and (3) perceived social support and actual social support.

\section{METHOD}

\section{Participants}

Twenty traumatic spinal cord injury survivors of workforce age, who were discharged from the Royal Talbot Rehabilitation Hospital in 2007, participated in the study. To be eligible, participants had to meet the three following criteria: medically stable post-SCI; persisting neurological loss; and workforce age (16-65 years). Ineligible participants met any or all of the following exclusion criteria: significant brain impairment (as entered on the hospital record for admission or discharge diagnoses); diagnosed severe psychiatric co-morbidity; or dependent upon 24-hour ventilation support. Of the 69 study-eligible SCI survivors, $20(29 \%)$ agreed to participate.

The majority of participants were male $(n=18)$, aged from 25-44 years when injured (see Table 1) and employed fulltime at the time of injury $(80 \%)$. Sixty percent of participants sustained paraplegia (see Table 2) and $65 \%$ of participants received some form of post-injury compensation (e.g., transport accident insurance, workers' compensation).

One year following hospital discharge, the majority of the sample $(40 \%)$ was still undergoing rehabilitation and another $20 \%$ were still in receipt of compensation. Twenty percent had secured full-time paid work (see Table 3 ). Thus, the sample was broadly representative of the Australian SCI population in terms of gender, injury age and compensation status.
Table 1. Age at Injury

\begin{tabular}{|c|c|c|}
\hline Age Group & Frequency & Percent (\%) \\
\hline \hline 15-24 years & 6 & 30.0 \\
\hline 25-44 years & 9 & 45.0 \\
\hline 45-60 years & 5 & 25.0 \\
\hline Total & $\mathbf{2 0}$ & $\mathbf{1 0 0 . 0}$ \\
\hline
\end{tabular}

Table 2. Impairment Level

\begin{tabular}{|c|c|c|}
\hline Impairment & Frequency & Percent (\%) \\
\hline \hline Complete paraplegia & 8 & 40.0 \\
\hline Incomplete paraplegia & 4 & 20.0 \\
\hline Complete quadriplegia & 4 & 20.0 \\
\hline Incomplete quadriplegia & 4 & 20.0 \\
\hline Total & $\mathbf{2 0}$ & $\mathbf{1 0 0 . 0}$ \\
\hline
\end{tabular}

Table 3. Post-Injury Rehabilitation Outcomes at 12-Month Follow-Up

\begin{tabular}{|c|c|c|}
\hline Rehabilitation Outcome & Frequency & Percent (\%) \\
\hline \hline Rehabilitation program & 8 & 40.0 \\
\hline Paid employment & 4 & 20.0 \\
\hline On compensation & 4 & 20.0 \\
\hline Other* & 4 & 20.0 \\
\hline Total & $\mathbf{2 0}$ & $\mathbf{1 0 0 . 0}$ \\
\hline
\end{tabular}

*Other category comprises voluntary work, unemployed, student, retired.

\section{Instruments}

\section{Injury Severity}

Functional ability at discharge from hospital was assessed with the 'Functional Independence Measure' (FIM). Patients are rated on observed, actual behaviour rather than capability across 18 everyday activities, such as bathing, eating and dressing. Scale scores range from 1 to 7 and represent three categories of functional independence: complete dependence (scores 1 - 2); modified dependence (scores 3 - 5) and independence (scores 6 - 7) [49].

\section{Social Support Measures}

Psychometrically validated scales, which assessed the three major types of social support (perceived, actual and structural) were used to evaluate their differential impact on post-injury daily functioning at follow-up 12-months postdischarge. The psychometric properties of these scales have been well-reported (see McDowell [22], for a good summary).

\section{Perceived Social Support}

The 'Perceived Social Support Scale' [1] assesses two aspects of perceived social support: (1) the perceived 
availability of social support and (2) satisfaction with available social support [50]. Thus, the scale specifically focuses on the number of people to whom individuals can turn for support in specified situations and the level of satisfaction with the support provided. As the Perceived Social Support Scale [1] assesses the satisfactoriness of a range of social interactions, including those with significant others (i.e. social integration) and the wider community (i.e., community integration), as well as the level of social support (i.e., actual social support), it was deemed the most appropriate measure to assess the subjective component of structural social support and actual social support.

\section{Structural Social Support}

Due to the finding that the two most common forms of structural social support - community integration and social integration - are essentially unrelated [4], they were assessed separately.

a. Community integration. The 'Community Integration Measure (CIM)' [51] is a psychometrically sound instrument that assesses the extent of community participation and integration using a self-report 10item scale. A single summary score is derived from the unweighted sum of the 10 items, with higher scores representing greater community integration. Unlike other community support measures, the CIM does not assume an hierarchical view of the relative value or importance of different types of relationships or activities [50, 51].

b. Social integration. The Craig Handicap Assessment and Reporting Technique (CHART) [52] is a selfreport instrument which measures handicap among community-dwelling SCI rehabilitation participants. Its focus is on objective easily quantifiable criteria. Handicap is assessed across six domains: physical independence; mobility; occupation; social integration; economic self-sufficiency and cognitive independence. The Social Integration subscale of the CHART instrument was extracted for the present study. The Social Integration subscale assesses participation in, and maintenance of, an array of social relationships including those with relatives, romantic partners, housemates, friends, business associates and strangers [27].

\section{Actual Social Support}

The 'Rand Social Health Battery' [53] supplies an overall, objective measure of social functioning. Ten questions evaluate the level of social support and the frequency of different types of social interactions (e.g., visits and phone calls). Unlike other instruments, the RAND acknowledges the beneficial aspect of social interactions as well as the negative impact of excessive social interactions [22].

\section{Post-Injury Daily Functioning Ability}

The 'WHO Disability Schedule II' (WHODAS) [54] provides a functional profile derived from scores obtained for day-to-day functioning across six domains. Based upon participants' responses, difficulty in performing tasks in six key domains is assessed: household and work activities; getting around; self-care; participation in society; getting along with others; understanding and communicating. The WHODAS has been subjected to rigorous empirical testing [e.g., 55, 56], and is frequently used as an outcome variable in serious traumatic studies [e.g., 57, 58].

\section{Study Design and Procedure}

A prospective design was used. Participants were interviewed within one week of hospital discharge to assess injury severity and social support, using a structured interview pro-forma. Demographic data were also collected. One year later, a follow-up assessment was conducted to evaluate post-injury performance of everyday tasks across a variety of domains (the main outcome variable). Ethics approval for the research was obtained from the Ethics Committees of the Faculty of Health Sciences, LaTrobe University and Austin Hospital, Melbourne, Australia. Informed written consent was obtained from all participants.

\section{Statistical Analyses}

Two sets of statistical analyses were performed. Firstly, bivariate analyses using Pearson's correlation were performed to examine the associations between the three major types of social support and daily functioning. Secondly, multivariate (regression) analyses were conducted to identify which subjective-objective social support dyad (comprising subjective perceived social support and one other type of objective social support) was the best predictor of a successful post-injury rehabilitation outcome.

\section{RESULTS}

\section{Bivariate Analyses}

Pearson's correlation was used to examine associations between each of the three major types of social support and daily functioning (as measured by the WHODAS II).

\section{Associations Between the Major Types of Social Support and Daily Functioning}

In the following regression models, the dependent variable was post-injury daily functioning (i.e., WHODAS scores). The two independent variables were a subjective measure of social support (i.e., perceived social support scores) and an objective social support (i.e., actual social support or community integration or social integration scores).

All of the social support variables were associated with daily functioning ability (see Table 4). In particular, higher levels of perceived social support $(\mathrm{r}=-.65, \mathrm{p}<.01, \mathrm{n}=20)$ and greater community integration $(\mathrm{r}=.63, \mathrm{p}<.01, \mathrm{n}=20)$ were significantly associated with better day-to-day functioning, separately accounting for approximately $40 \%$ of the total variance. Moderate correlations, which approached significance, were found for higher social integration $(\mathrm{r}=-.44, \mathrm{p}=.05, \mathrm{n}=20)$, and greater levels of actual social support $(\mathrm{r}=-.44, \mathrm{p}=.053, \mathrm{n}=20)$, with better day-to-day functioning.

\section{Injury Severity as a Lurking Variable}

A significant, negative association was found between injury severity (FIM scores) and difficulty with daily task performance (WHODAS II scores) $\mathrm{r}=-.68, \mathrm{p}<.01, \mathrm{n}=20,2$ tailed, indicating that SCI survivors with less severe injuries 
were better able to independently perform daily tasks. Therefore, partial correlations which controlled for injury severity were conducted to assess the relationship between social support and daily task performance independent of injury severity. As can be seen from Table 5, only perceived social support remained significant.

Table 4. Associations Between Social Support Type and PostInjury Daily Functioning

\begin{tabular}{|c|c|c|}
\hline Rehabilitation Outcome & r & Sig \\
\hline \hline Perceived social support & $-.65^{*}$ & $.006^{* *}$ \\
\hline Community integration & $.63^{*}$ & $.007^{* *}$ \\
\hline Social integration & -.44 & .050 \\
\hline Actual social support & -.44 & .053 \\
\hline
\end{tabular}

Table 5. Association between Social Support Type and PostInjury Daily Functioning when Controlling for Injury Severity

\begin{tabular}{|c|c|c|}
\hline Rehabilitation Outcome & $\mathbf{r}$ & Sig \\
\hline \hline Perceived social support & $-.56^{*}$ & $.013^{*}$ \\
\hline Community integration & .40 & .092 \\
\hline Social integration & -.41 & .083 \\
\hline Actual social support & -.35 & .137 \\
\hline
\end{tabular}

Note: some correlations are negative due to reverse scoring; ${ }^{*} \mathrm{p}<.05 ; \mathrm{Df}=17$.

\section{Multivariate Analyses}

Simultaneous multiple regression analyses were performed to assess the ability of subjective-objective social support dyads to predict post-injury daily functioning. The multiple correlation coefficients for each perceived social support dyad were significant and moderately large ranging from $\mathrm{R}=.79$ for perceived social support and community integration to $\mathrm{R}=.66$ for perceived social support and actual social support.

The most effective subjective-objective social support dyad for predicting better daily functioning 12-months postdischarge was perceived social support and community integration, $F(2,17)=14.02, \mathrm{p}<.001$, which accounted for $62 \%$ of the total variance (see Table 6). Perceived social support contributed greater unique variance $\left(\mathrm{sr}^{2}\right)$ to the overall variance $\left(\mathrm{R}^{2}\right)$ than did community integration (.34 vs .20 , respectively).

Table 6. The Dyad of Perceived Social Support and Community Integration as a Predictor of PostInjury Daily Functioning

\begin{tabular}{|c|c|c|c|c|c|}
\hline Rehabilitation Outcome & $\boldsymbol{B}$ & $\boldsymbol{S E} \boldsymbol{B}$ & $\boldsymbol{\beta}$ & $\boldsymbol{p}$ & $\mathbf{s r}^{2}$ \\
\hline \hline Perceived social support & -15.58 & 4.92 & -.50 & $.006^{* *}$ & .34 \\
\hline Community integration & 1.10 & .37 & .47 & $.008^{* *}$ & .20 \\
\hline Note: $* * \mathrm{p}<.01 ; \mathrm{R}=.79 ; \mathrm{R}^{2}=62$.
\end{tabular}

The second most effective subjective-objective social support dyad comprised perceived social support and social integration, $F(2,17)=7.84, \mathrm{p}<.01$, which accounted for $48 \%$ of total variance found for post-injury day-to-day functioning ability (see Table 7). The unique variance $\left(\mathrm{sr}^{2}\right)$ contributed by perceived social support to the total variance $\left(\mathrm{R}^{2}\right)$ was over 4.5 times greater than that contributed by social integration.

Table 7. The Dyad of Perceived Social Support and Social Integration as a Predictor of Post-Injury Daily Functioning

\begin{tabular}{|c|c|c|c|c|c|}
\hline $\begin{array}{c}\text { Rehabilitation } \\
\text { Outcome }\end{array}$ & $\boldsymbol{B}$ & $\boldsymbol{S E \boldsymbol { B }}$ & $\boldsymbol{\beta}$ & $\boldsymbol{p}$ & $\mathbf{s r}^{2}$ \\
\hline \hline $\begin{array}{c}\text { Perceived social } \\
\text { support }\end{array}$ & -17.64 & 5.80 & -.56 & $.007 * *$ & .28 \\
\hline Social integration & -.22 & .16 & -.26 & .184 & .06 \\
\hline Note: ** $\mathrm{p}<.01 ; \mathrm{R}=.69 ; \mathrm{R}^{2}=48$.
\end{tabular}

The third most effective subjective-objective social support dyad comprised perceived social support and actual social support $F(2,17)=6.63, \mathrm{p}<.01$, accounting for $44 \%$ of the total variance found for daily functioning ability (see Table 8). The unique variance $\left(\mathrm{sr}^{2}\right)$ contributed by perceived social support to the total variance $\left(\mathrm{R}^{2}\right)$ was more than 12 times greater than that contributed by actual social support.

Table 8. The Dyad of Perceived Social Support and Actual Social Support as a Predictor of Post-Injury Daily Functioning

\begin{tabular}{|c|c|c|c|c|c|}
\hline Rehabilitation Outcome & $\boldsymbol{B}$ & $\boldsymbol{S E B}$ & $\boldsymbol{\beta}$ & $\boldsymbol{p}$ & $\mathbf{s r}^{\mathbf{2}}$ \\
\hline \hline Perceived social support & -17.94 & 6.58 & -.57 & $.014 *$ & .25 \\
\hline Actual social support & -.41 & .57 & -.15 & .484 & .02 \\
\hline Note: ${ }^{*} \mathrm{p}<.05 ; \mathrm{R}=.66 ; \mathrm{R}^{2}=44$.
\end{tabular}

\section{DISCUSSION}

The twin aims of this prospective, exploratory study were to investigate (1) the association between the three major forms of social support (perceived, actual and structural) on successful rehabilitation among survivors of traumatic spinal cord injury (SCI) one-year post-discharge using psychometrically sound measures, and (2) the ability of three social support dyads (comprising a subjective and objective component) to predict rehabilitation outcome among SCI survivors. Rehabilitation outcome was assessed using the WHODAS II which measures successful daily functioning across six key domains (household and work activities; getting around; self-care; participation in society; getting along with others; understanding and communication).

Although each of the three major types of social support was associated with a better rehabilitation outcome, they were not equally so. Perceived social support was the most strongly related to successful post-injury daily functioning, which confirms the suggestion that perceived social support forms the crux of social support and is more important than 
actual social support [46]. Furthermore, after controlling for injury severity, perceived social support alone remained significantly correlated with post-injury daily functioning. These results support the notion that perceived social support is a fairly stable construct which may be related to enduring characteristics, such as adult attachment style [39, 59, 60].

Analyses of the predictive ability of the three subjectiveobjective social support dyads revealed that the subjective component contributed greater unique variance to the overall predictive ability of the model than did the accompanying objective component. These results confirm stress-adaptation models which suggest that the effect of stress is moderated by an individual's evaluation or cognitive appraisal of the stress [14]. However, the ratio between the contribution made by the objective and subjective components of each of the three social support dyads differed markedly. Subjective perceptions of social support contributed approximately 1.5 times that of objectively measured community integration, 4.5 times that of objectively measured social integration and 12 times that of objectively measured actual social support. As adaptation to serious traumatic spinal cord injury is a continual process, these results provide insight into the declining importance of (objectively measured) actual social support and the support provided by friends and family for effective daily task performance as post-injury adaptation increases (e.g., Wilcox et al., 1994). However, subjective perceptions of availability of support from these sources are more predictive of successful rehabilitation, suggesting a 'safety net' effect, that is, help is available if needed. Thus, the availability of social support may facilitate adjustment by "altering the cognitive appraisal of events" (Wills \& Shinar, 2000, p. 89) [61].

Of the three subjective-objective social support dyads, the model comprising perceived social support and community integration was the best predictor of improved daily functioning, accounting for $62 \%$ of the variance found for difficulty in performing daily tasks. It may be that SCI survivors have sufficiently adjusted to their disability oneyear post injury to widen their scope and participate in the wider community. This interpretation is supported by the considerably smaller correlation between successful daily functioning and social integration (i.e., with personal and local networks), which are more prominent in the early stages of rehabilitation [4, 23] while the smaller (and practically significant) association between actual social support and post-injury daily functioning suggests a lower need for practical support, which may not be as critical for daily functioning one-year post-injury.

Thus, the present results suggest that SCI survivors' focus one-year post-injury expanded to include re-integration into the wider community, however, this development requires high levels of subjectively assessed perceived social support to be successful. Theoretically, these results support the two main opposing causal models that explain the relationship between social support and recovery from injury. The Main Effects Model posits that structural social support (i.e., community integration) exerts a direct effect on well-being by increasing social support access and inducing positive mental states. In contrast, the Stress Buffering Model hypothesizes that perceptions of social support (i.e., perceived social support) act as a buffer against the damaging effects of stress and enhance coping ability [14, 62-64]. Therefore, social support may simultaneously operate along two pathways - direct (i.e., objective) and indirect (i.e., subjective) - rather than one or the other. Integrated theories that incorporate both aspects of social support (i.e., objective and subjective) may provide a fuller explanation of its effect on recovery from injury. From both a practitioner and researcher perspective, these results suggest that social support may account for a substantial portion of the unexplained variance found for functional outcome following traumatic SCI (clinical and demographic factors traditionally account for only approximately $35 \%$ of the variance $[47,48])$.

\section{LIMITATIONS}

The small sample size $(n=20)$ is an obvious study limitation, particularly when using multiple correlation techniques, such as multiple regression, which produce more stable results with a better ratio of subjects to variables. However, the study was exploratory in nature, the sample was broadly representative of the Australian SCI population and the effect sizes obtained in the analyses were large to moderate indicating that results may be robust.

\section{FUTURE RESEARCH DIRECTIONS}

As adaptation to serious traumatic spinal cord injury is a continual process, future research could examine which subjective-objective social support dyad predicts successful outcomes at different stages of rehabilitation. For example, the dyad of perceived social support and social integration (which comprises support from family and close friends) may be more important in the earlier stages of adjustment [4]. Although wide individual and group differences exist (e.g., age-related or injury type), future research could also usefully determine the threshold at which the number of social network ties becomes disadvantageous to rehabilitation outcomes. Optimal network sizes may also differ according to the type (e.g., social, community or webbased) and medium (e.g., in-person, telephone or electronic) of interactions. Social support measures could be developed that incorporate both objective and subjective items relevant to each of the three major types of social support. However, these measures would need to focus on a particular welldefined type of social support (e.g., actual or structural) and psychometric properties would need to be rigorously assessed. As social and community integration measure different dimensions of structural social support, different measures would need to be developed for each [4].

\section{CONCLUSION}

Although social support is frequently measured as a unidimensional construct, in real life, it is an interdependent and compound construct [14]. From a research perspective, the effectiveness of social support may be best measured by adopting a multiple-measure approach, that is, using psychometrically sound scales that provide both a subjective and objective assessment of social support. From a theoretical perspective, the present results suggest that social support may promote well-being using both direct (objective) and indirect (subjective) pathways. Therefore, it is proposed that the use of subjective-objective social support dyads may impart a fuller understanding of the 
contribution of social support to the prediction of rehabilitation outcome.

\section{ACKNOWLEDGEMENT}

None declared.

\section{CONFLICT OF INTEREST}

None declared.

\section{REFERENCES}

[1] Sarason IG, Sarason BR, Shearin EN, and Pierce GR. A brief measure of social support: practical and theoretical implications. J Soc Pers Relat 1987; 4: 497-610.

[2] Vaux A, Harrison D. Support network characteristics associated with support satisfaction and perceived support. Am J Community Psychol 1985; 13: 245-68.

[3] Barrera M. Distinctions between social support concepts, measures and models. Am J Community Psychol 1985-1986; 14: 413-445.

[4] Murphy GM, O'Hare MA, and Willis L. The relationship among different types of social support accessed by traumatic spinal cord injury survivors. Int J Disabil Manag 2010; 5: 59-66.

[5] Schwarzer R, Leppin A. Social support and health: a theoretical and empirical overview. J Soc Pers Relat 1991; 9: 51-64.

[6] Chronister JA, Johnson EK, and Berven NL. Measuring social support in rehabilitation. Disabil Rehabil 2006; 28: 75-84.

[7] Schwarzer R, Leppin A. Social support and mental health: a conceptual and empirical overview. In: Montada LS, Fillip S, Lerner M, Eds. Life crisis and experiences of loss in adulthood New Jersey: Lawrence Erlbaum Associates 1992; 435-58.

[8] McColl MA, Skinner H. Assessing inter- and intrapersonal resources: social support and coping among adults with a disability. Disabil Rehabil 1995; 17: 24-34.

[9] Rook K. The negative side of social interaction: Impact on psychological well-being. J Pers Soc Psychol 1984; 46: 1097-108.

[10] Rook KS. Detrimental aspects of social relationships: taking stock of an emerging literature. In: Veiel HOF, Baumann U, Eds. The meaning and measurement of social support, New York: Hemisphere 1992: pp. 157-69.

[11] Seeman TE. Social ties and health: The benefits of social integration. Ann Epidemiol 1996; 6: 442-51.

[12] Cobb S. Presidential address - 1976. Social support as a moderator of life stress. Psychosom Med 1976; 38: 300-14.

[13] Cohen S, Underwood LG, and Gottlieb BH. Social support measurement and intervention: A guide for health and social scientists. New York: Oxford University Press 2000.

[14] Cohen S, Wills TA. Stress, social support, and the buffering hypothesis. Psychol Bull 1985; 98: 310-57.

[15] Gore S. The effect of social support in moderating the health consequences of unemployment. J Health Soc Behav 1978; 19: $157-65$.

[16] Häggström A, Lund ML. The complexity of participation in daily life: A qualitative study of the experiences of persons with acquired brain injury. J Rehabil Med 2008; 40: 89-95.

[17] Aneshensel CS, Stone JD. Stress and depression: a test of the buffering model of social support. Arch Gen Psychiatry 1982; 39: 1392-6.

[18] Kessler RC, Turner JB, and House JS. Effects of unemployment on health in a community survey: Main, modifying, and mediating effects [Abstract]. J Social Issues 1988; 44: 69-85.

[19] McKee-Ryan FM, Song Z, Wanberg R, and Kinicki AJ. Psychological and physical well-being during unemployment: a meta-analytic study. J Appl Psychol 2005; 90: 53-76.

[20] Elfstrőm ML, Ryden A, Persson L-O, and Sulivan M. Effects of coping on psychological outcome when controlling for background variables: a study of traumatically spinal cord lesioned persons. Spinal Cord 2002; 40: 408-15.

[21] Elfstrőm ML, Ryden A, Kreuter M, Taft C, and Sullivan M. Relations between coping strategies and health-related quality of life in patients with spinal cord lesion. J Rehabil Med 2005; 37: 916

[22] McDowell I. Measuring health: A guide to rating scales and questionnaires $\left(3^{\text {rd }}\right.$ ed). New York: Oxford University Press Inc 2006.
[23]

Wilcox VL, Kasl SV, Berkman LF. Social support and physical disability in older people after hospitalization: a prospective study. Health Psychol 1994; 13: 170-9.

[24] Hegelson VS. Two important distinctions in social support: Kind of support and perceived versus received. J Appl Soc Psychol 1993; 23: $825-45$

[25] Berkman LF. Assessing the physical health effects of social networks and social support. Annu Rev Public Health 1984; 5: 41332.

[26] Sarason IG, Sarason BR, Pierce GR. Social support: global and relationship-based levels of analysis. J Soc Personal Relat 1994; 11: 295-312.

[27] Whiteneck G. Validated measures of participation and the environment form Craig Hospital: CHART and CHIEF. International Seminar on the Measurement of Disability. New York 4-6 June, 2001.

[28] Anderson CJ, Krajci KA, and Vogel LC. Community integration among adults with spinal cord injuries sustained as children or adolescents. Dev Med Child Neurol 2003; 45: 129-34.

[29] Dalgard OS. Social support definition and scope. 19 November, 2009 [cited 2009] Available from www.euphix.org.

[30] Berkman LF. The role of social relations in health promotion. Psychosom Med 1995; 57: 245-54.

[31] Kawachi I, Colditz GA, Ascherio A, et al. A prospective study of social networks in relation to total mortality and cardiovascular disease in men in the USA. J Epidemiol Community Health 1996; 50: $245-51$.

[32] Ramsay S, Ebrahim S, Whincup P, et al. Social engagement and the risk of cardiovascular mortality: Results of a prospective population-based study of older men. Ann Epidemiol 2008; 18: 476-83.

[33] Lund ML, Nordlund A, Nygard L, Lexel J, Bernspang B. Perceptions of participation and predictors of perceived problems with participation in persons with spinal cord injury. J Rehabil Med 2005; 37: 3-8,

[34] Ben-Sira Z. Loss, stress and readjustment: the structure of coping with bereavement and disability. Soc Sci Med 1983; 17: 1619-32.

[35] Oxley D, Barrera JM, Sadalla EK. Relationships among community size, mediators, and social support variables: A path analytic approach. Am J Community Psychol 1981; 9: 637-51.

[36] Kalinsky R. The effect of social support on vocational rehabilitation outcome for individuals with disabilities. PhD [dissertation]. New York: City University of New York 2002.

[37] Sarason BR, Shearin EN, Pierce GR, and Sarason IG. Interrelations of social support measures: theoretical and practical implications. J Pers Soc Psychol 1987; 52: 813-32.

[38] Prociando M, Heller K. Measures of perceived social support from friends and from family: three validation studies. Am J Community Psychol 1983; 11: 1-24.

[39] Sarason IG, Sarason BR, and Shearin EN. Social support as an individual difference variable: Its stability, origins and relational aspects. J Pers Soc Psychol 1986; 50: 845-55.

[40] Cohen S, Hoberman H. Positive events and social supports as buffers of life stress. J Appl Soc Psychol 1983; 12: 99-125.

[41] Veiel H, Baumann U. The meaning and measurement of social support. New York: Hemisphere Publishing Corporation 1992.

[42] Hampton NZ. The affective aspect of subjective well-being among Chinese people with and without spinal cord injuries. Disabil Rehabil 2008; 30: 1473-9.

[43] Hirsch B. Natural support systems and coping with major life changes. Am J Community Psychol 1980; 8: 150-72.

[44] Wethington E, Kessler RC. Perceived social support, received social support, and adjustment to stressful life events. J Health Soc Behav 1986; 27: 78-89.

[45] Brouwer S, Reneman MF, Bültmann U, van der Klink JJL, Groothoff JW. A prospective study of return to work across health conditions: Perceived work attitude, self-efficacy and perceived social support. J Occup Rehabil 2010; 20: 104-12.

[46] Antonucci TC, Israel BA. 'Veridicality of social support: a comparison of principal and network members' responses'. J Consult Clin Psychol 1986; 54: 432-7.

[47] Krause J. Years to employment after spinal cord injury. Arch Phys Med Rehabil 2003; 84: 1282-9.

[48] Meade M, Lewis A, Jackson M, Hess D. Race, employment and spinal cord injury. Arch Phys Med Rehabil 2004; 85: 1782-92. 
[49] Amundson J, Brunner A, Ewers M. FIM scores as an indicator of length of stay and discharge destination in CVA patients: a retroactive outcomes study. 2007 [cited 2009] Available from: http://murphylibrary.uwlax.edu/digital/jur/2000/amundson-brunnerewers.pdf

[50] Radomski MV, Latham CAT. Occupational therapy for physical dysfunction. Baltimore USA: Walters Klower 2007.

[51] McColl M, Davies D, Carlson P, Johnston J, Minnes P. The community integration measure. Arch Phys Med Rehabil 2001; 82: 429-34.

[52] Whiteneck GG, Brooks CA, Charlifue S, et al. The Craig handicap assessment and reporting technique. Englewood: Denver Company Craig Hospital 1992.

[53] Donald CA, Ware JE. The quantification of social contacts and resources. (R-2937-HHS). Santa Monica, CA: RAND Corporation 1982.

[54] World Health Organization. WHODAS II. 2001, [cited 2008]. Available from: http://www.who.int/icidh/whodas/index.html

[55] Frederici S, Meloni F, Mancini A, Lauriola M, Belardinelli O. World Health Organization disability assessment schedule II: contribution to the Italian validation. Disabil Rehabil 2009; 31: 553-64.

[56] Posl M, Cieza A, Stucki G. Psychometric properties of the WHODASII in rehabilitation patients. Qual Life Res 2007; 16: 1521-31.
[57] O'Donnell ML, Holmes AC, Creamer MC, et al. The role of posttraumatic stress disorder and depression in predicting disability after injury. Med J Aust 2009; 190: S71-S4.

[58] Svestkova O, Angerova Y, Sladkova P, Bickenbach JE, and Raggi A. Functioning and disability in traumatic brain injury. Disabil Rehabil 2010; 32: S68-S77.

[59] Moreira JM, De Fatima Silva M, Moreira C, et al. Perceived social support as an offshoot of attachment style. Pers Individ Dif 2003; 34: 485-501.

[60] Priel B, Shamai D. Attachment style and perceived social support: effects on affect regulation. Pers Individ Dif 1995; 19: 235-41.

[61] Wills TA, Shinar O. Measuring perceived and received social support. In Cohen S, Underwood LG, and Gottlieb BH, Eds. Social support measurement and intervention: A guide for health and social scientists. New York: Oxford University Press 2000; pp. 86135

[62] Cohen S. Psychosocial models of the role of social supporting the etiology of physical disease. Department of Psychology (Paper 262) 1988. Available from http://www.repository.cmu.edu/psycho $\log / 262$

[63] Cohen S, McKay G. Social support, stress and the buffering hypothesis: A theoretical analysis. In: Baum A, Taylor SE, and Singer JE, Eds. Handbook of psychology and health. Hillsdale, NJ: Erlbaum \& Associates 1984; pp. 253-67.

[64] Kawachi I, Berkman LF. Social ties and mental health. J Urban Health 2001; 78: 458-67.

(c) O'Hare et al.; Licensee Bentham Open.

This is an open access article licensed under the terms of the Creative Commons Attribution Non-Commercial License (http: //creativecommons.org/licenses/by$\mathrm{nc} / 3.0 /$ ) which permits unrestricted, non-commercial use, distribution and reproduction in any medium, provided the work is properly cited. 